\title{
A Peptide Enhancement Strategy in Alzheimer's Disease: Pilot Study with TRH-Physostigmine Infusions
}

\author{
Alan M. Mellow, Stephen M. Aronson, Bruno Giordani, and Stanley Berent
}

\section{Introduction}

Although disruption in several neurochemical systems has been described in Alzheimer's disease (AD), the most robust evidence relates the corc cognitive impaiment to significant deficits in brain acetylcholine function (Coyle et al 1983). The cholinergic hypothesis of AD has led to treatment strategies aimed at enhancing central cholinergic neurotransmission (Bartus et al 1982). There is modest improvement in cognition after treatment with centrally active acetylcholinesterase inhibitors, such as physostigmine (Davis and Mohs 1982; Thal et al 1989). Enhancing the efficacy of cholinergic agents would provide a novel therapeutic approach based on the cholinergic hypothesis. One possibility is coadministration of a cholinomimetic drug with a neuromodulatory agent known to augment cholinergic activity. The important role for neuropeptides in the modulation of brain neurotransmitter function is well established (Hokfelt et al 1989); thus, a "procholinergic" modulatory neuropeptide might serve as a basis for such an approach.

In addition to its role in the regulation of thyroid function, thyrotropin-releasing hormone (TRH) has long been recognized as a modulatory neuiopeptide in the central nervous system (Horita et al 1986). The procholinergic effects of TRH have been demonstrated in animal studies at several levels of organization in the central nervous system (Yarbrough 1983). We have previously shown (Mellow et al 1989) that TRH can be given safely in high doses (required for central nervous sy'stem effects) to $A D$ patients and produces behavioral activation and a small improvement in semantic memory. We have also shown it to reverse scopolamine-induced cognitive impairment in normal volunteers (Molchan et al 1990). We are currently testing the safety and feasibility of a peptide enhancement strategy, examining the cognitive and neuroendocrine effects of high-dose TRH in combi-

From the Department of Psychiatry (AMM, SMA, BG, SB) and Michigan Alzheimer's Disease Research Center (AMM, BG, SB), University of Michigan Medical School; and Psychiatry Service. Ann Artor VA Medical Center (AMM, SMA), Ann Arbor, MI.

Presented in part at 47th Annual Meeting of the Society of Biological Psychiatry, Washington, DC, May 1, 1992.

Address reprint requests to Alan M. Mellow, M.D., Ph.D. Department of Psychiatry, University of Michigan, 900 Wall Street. Ann Arbor, MI 48105.

Received January 25, 1993; revised May 12. 1993. nation with physostigmine in $A D$ patients. We herein report our initial experience in the first six subjects, in which we have tested the safety of this combination, as well as the hypothesis that TRH might modulate the effects of physostigmine.

\section{Methods}

Six patients (four men and two women; mean age, $69 \pm 7$ years), taking no psychotropic medications and in good general health, who met NINCDS-ADRDA criteria for probable Alzheimer's disease (McKhann et al 1984) underwent two separate study days (separated by at least 48 hours) while they were inpatients at the University of Michigan Hospital Clinical Research Center. Patients all received pretreatment with glycopyrrolate $(0.1-0.2 \mathrm{mg})$, a peripheral cholinergic antagonist. Patients (blinded to drug treatment conditions) then received (on randomized days) a 10min intravenous infusion of TRH $(0.1$ or $0.3 \mathrm{mg} / \mathrm{kg})$ or placebo, followed by a $30-\mathrm{min}$ infusion of physostigmine $(0.5$ or $1.0 \mathrm{mg}$ ). Patients had continuous electrocardiogram and vital sign monitoring during and at least $I$ hour after the drug infusions. Cognitive testing was performed each study day, prior to drug infusions and during the last 10-15 minutes of the physostigmine infusions, by a technician blinded to drug treatment condition. The psychometric battery included the Buschke Selective Reminding Task, a letter retrieval task (a measure of verbal fluency), a picture memory test (a measure of automatic leaming), and a digit span task. Patients were also asked to perform self-ratings (1-5 scale) on measures of arousal and mood. Serial blood samples for neuroendocrine measures of central cholinergic activity were obtained prior to, during, and after drug infusions. Samples were collected in chilled ethylene glycol tetraacetic acid (EGTA)treated tubes, centrifuged at $4^{\circ} \mathrm{C}$, and plasma was stored at $-80^{\circ} \mathrm{C}$ until processing. Epinephrine was measured by modification of the method of Bouloux et al (1985), using high-pressure liquid chromatography with electrochemical detection. $\beta$-Endorphin was measured by immunoradiometric assay (Voellmy et al 1988) (kits purchased from Nickels Institute, San Juan Capistrano, CA).

Results of the cognitive and behavioral testing, as well as peak hormonal response and maximum vital sign changes, were all expressed as change scores (postinfusion minus preinfusion) for each day and analyzed by paired -test, comparing the phy- 
sostigmine day with the physostigmine plus TRH day for each patient. Three patients received physostigmine, $0.5 \mathrm{mg}$, plus TRH, $0.1 \mathrm{mg} / \mathrm{kg}$, (or placebo) and three patients received physostigmine, $1.0 \mathrm{mg}$, plus TRH, $0.3 \mathrm{mg} / \mathrm{kg}$, (or placebo). Due to the small number of subjects, combined data were analyzed from all six subjects. In this preliminary study, corrections for multiple $t$-tests were not used.

\section{Results}

All patients tolerated the infusions without adverse effects on their vital signs or electrocardiogram. The only side effects experienced were some nausea (in two patients) and transient shivering (in three patients, those receiving the higher TRH dose). Putients' self-ratings of mood and arousal did not change between the physostigmine day and physostigmine plus TRH day. Systolic blood pressure increases were significantly greater on the physostigmine plus TRH day, compared with the physostigmine day $(26.8 \pm 4.9 \mathrm{~mm} \mathrm{Hg}$ versus $14.3 \pm 3.0 \mathrm{~mm} \mathrm{Hg}$ ). There were no significant changes in any other vital signs. Patients performed significantly better on measures of verbal fluency on the physostigmine plus TRH day than on the physostigmine day. In addition, patients had significantly fewer verbal intrusion errors on the phy'sostigmine plus TRH day. On measures of delayed recall (word list learning), immediate recall (digit span), and automatic learning, there was no significant difference in performance between days. Although TRH improved performance on two cognitive measures, the overall response to physostıgmine in this patient sample was nonsign:ficant (data not shown). Peak plasma epinephrine response dunug and after physostigmine infusion was significantly increased on the physostigmine plus TRH days. The $\beta$-endorphin response showed no significant difference between days and was quite variable in this sample; only three of six patients showed any rise in $\beta$-endorphin after drug infusions. The results are summarized in Table 1.

\section{Discussion}

This pilot study represents the f:rst attempt at a peptide enhancement strategy in $A D$, using the procholinergic neuropeptide TRH in combination with the cholinesterase inhibitor physostigmine.
We have found this combination to be safe and well tolerated in AD patients. The increases in blood pressure seen after both physostigmine and the combination of TRH plus physostigmine are consistent with both our own previous work (Melluw et al 1989) and that of others (Janowsky et al 1985). Although we did not include a day in this study when TRH was administered alone, the magnitude of the blood pressure change on the physostigmine plus TRH day suggests that the pressor effects of the two drugs are not synergistic, thereby reinforcing the safety of this strategy. On two rieasures of cognitive function, TRH improved performance when coadministered with physostigmine. These results are encouraging, because TRH appeared to have some enhancing effect even when the overall response to phy. sostigmine was nonsignificant (which suggests nonoptimal physostigmine dosing in this patient sample). Because of the apparent biphasic dose-response curve for the effects of physostigmine (Davis and Mohs 1982; Mohs and Davis 1982), a rigorous test of any cholinergic enhancement strategy will require adequate dose-finding for each subject, to determine a best dose of physostigmine to be coadministered with high-dose TRH. Under these conditions, coadministration of TRH with physostigmine might yield more robust findings. Another limitation of the current study is the lack of test days in which patients received either placebo alone or TRH alone. Such a design would allow a more precise dissection of potential enhancing effects of TRH. Lacking this, however, the cognitive effects in patients receiving physostigmine plus TRH still suggest an enhancement, because the paltern of improvement (decrease in intrusion errors) differs fro:n that seen with TRH alone in our previous work (Mellow et al 1989).

It has been suggested that the plasma epinephrine response to physostigmine is mediated via a central cholinergic mechanism (Kennedy et al 1984). This response, as well as the $\beta$-endorphin response has been shown to be blunted in AD (Raskind et al 1989); the increase in peak epinephrine after high-dose TRH coadministration might reflect a central marker of cholinergic enhancement, which could be correlated in future studies with results of behavioral and cognitive measurements. The lack of a test day with TRH alone makes these results somewhat complex to interpret. Although peripherally administered TRH does not

Table 1. Acute Effects of TRH-Physostigmine Infusions in Six Alzheimer's Disease (AD) Patients ${ }^{u}$

\begin{tabular}{lrcc}
\hline \multicolumn{1}{c}{ Variable } & Physostigmine & Physostigmine + TRH & $p$ \\
\hline Verbal fluency (words) & $-0.7 \pm 0.4$ & $0.9 \pm 0.8$ & $<0.04$ \\
Intrusions (words) & $3.3 \pm 1.5$ & $-9.2 \pm 3.5$ & $<0.04$ \\
Recall (words) & $1.9 \pm 3.0$ & $-2.8 \pm 3.8$ & NS \\
Digit span (digits) & $-0.4 \pm 0.4$ & $-0.3 \pm 0.5$ & NS \\
Peak $\Delta$ systolic BP (mm Hg) & $14.3 \pm 3.0$ & $26.8 \pm 4.9$ & $<0.04$ \\
Peak $\Delta$ diastolic BP (mm Hg) & $15.8 \pm 2.4$ & $17.8 \pm 2.6$ & NS \\
Peak $\Delta$ pulse rate (bpm) & $10.7 \pm 3.8$ & $17.2 \pm 6.3$ & NS \\
Peak $\Delta$ epinephrine (pg/ml) & $23.9 \pm 15.7$ & $64.7 \pm 25.6$ & $<0.03$ \\
Peak $\Delta$ B-endorphin (pg/ml) & $30.2 \pm 16.5$ & $23.5 \pm 26.2$ & NS \\
\hline
\end{tabular}

"All variables are expressed as change scones (postdrug minus predrug) $\pm S E M$, and compared by paired t-test between days when patients received physostigmine alone and when they received physostigmine plus TRH. See text for details of drug administration and testing. TRH, thyrotropin-releasing bormone; NS, not significant. 
reliably produce plasma epinephrine increases (Morley et al 1981; Zaloga et al 1984), there is evidence that centrally administered TRH and its analogs increases epinephrine levels (Kabayama et al 1985; Ishikawa et al 1990). Once again, a rigorous test of the utility of epinephrine response as a marker of TRH enhancement awaits a larger study in which the hormonal effects of TरH alone are studied in this paradigm. The lack of a significant $\beta$-endorphin response (which also may be cholinergically mediated) may be because the physostigmine dosing in this pilot study was not optimized.

Further studies are under way to characterize niore fully the dose requirements for this enhancement paradigm in AD. Future research might extend the time frame of treatment to jong-term,

\section{References}

Bartus RT, Dean RL III, Beer B, et al (1982): The cholinergic hypothesis of geriatric memory dysfunction. Science 217:408417.

Bouloux P, Perrett D, Besser GM (1985): Methodological considerations in the determination of plasma catecholamines by high-performance liquid chromatography with electrochemical detection. Ann Clin Biochem 22:194-203

Coyle JT, Price DL, DeLong MR (1983): Alzheimer's disease: a disorder of central cholinergic innervation. Science 219:11841190.

Davis KL, Mohs RC (1982): Enhancement of memory prucesses in Alzheimer's disease with multiple-dose intravenous physostigmine Am J Psychiatry 139:1421-1424.

Davis KL, Thal LJ, Gamzu ER, et al (1992): A double-blind, placebo-controlled multicenter study of tacrine for Alzheimer's disease. The Tacrine Collaborative Study Group. $N$ Engl J Med 327:1253-1259.

Farlow M, Gracon SI, Hershey LA, et al (1992): A controlled trial of tacrine in Alzheimer's disease. The Tacrine Study Group. JAMA 268:2523-2529.

Hokfelt T, Millhorn D, Seroogy K, et al (1989): Coexistence of peptides with classical neurotransmitters. Experientia Suppl 56:154-179.

Horita A, Carino MA, Lai H (1986): Pharmacology of thyrotropin releasing hormone. Ann Rev Pharmacol Toxicol 26:311332.

Ishikawa Y, Shimatsu A, Kato Y, et al (1990): Effects of intrathecal administration of thyrotropin releasing hormone and its analogue, DN 1417, on plasma glucose and catecholamine levels in conscious rats. Brain Res $514: 1-4$.

Janowsky DS, Risch SC, Huey LY, ct al (1985): Etfects of physostigmine on pulse, blood pressure, and serum epinephrine levels. Am J Psychiatry 142:738-740.

Kabayama Y, Kato Y, Tojo K, et al (1985): Central effects of DN1417, a novel TRH analog, on plasma glucose and catecholamines in conscious rats. Life Sci 36:1287-1294. combined drug administration, and the use of longer-acting analogs of both acetylcholinesterase inhibitors and TRH. The recent interest in the use of the oral cholinesterase inhibitor tacrine in AD (Farlow et al 1992; Davis et al 1992) renders this paradigm more timely in its clinical implications. Such work could lead to a novel treatment approach in the experimental pharmacology of AD.

Supported by grants M01 RR00042 (NIGMS); P50 AG08671 (NIA), and a Department of Veterans Affairs Merit Review grant to AMM.

The authors wish to acknowledge the assistance of Dr. M. Hariharan for performing the hormonal assays.

Kennedy B, Janowsky DS, Risch SC, et al (1984): Central cholinergic stimulation causes adrenal epinephrine release. J Clin Invest 74:972-975.

McKhann G, Drachman D, Folstein M, et al (1984): Clinical diagnosis of Alzheimer's disease: report of the NINCDSADRDA Work Group under the auspices of the Department of Health and Human Services Task Force on Alzheimer's Disease. Neurology 34:939-944.

Mellow AM, Sunderland T, Cohen RM, et al (1989): Acute effects of high-dose thyrotropin releasing hormone infusions in Alzheimer's disease. Psychopharmacology 98:403-407.

Mohs RC, Davis KL (1982): A signal detectability analysis of the effect of physostigmine on memory in patients with Alzheimer's disease. Neurobiol Aging 3:105-110.

Molchan SE, Mellow AM, Lawlor BA, et al (1990): TRH attenuates scopolamine-induced memory impairment in humans. Psychopharmacology 100:84-89.

Morley JE, Tuck ML, Mayes DM, et al (1981): Thyrotropinreleasing hormone increases plasma norepinephrine in man. Horm Res 14:18-23.

Raskind MA, Peskind ER, Veith RC, et al (1989): Neuroendocrine responses to physostigmine in Alzheimer's disease. Arch Gen Psychiatry 46:535-540.

Thal LJ, Masur DM, Blau AD, et al (1989): Chronic oral physostigmine without lecithin improves memory in Alzheimer's disease. J Am Geriatr Soc 37:42-48.

Voellmy DR, Kulling P, Gramsch C, et al (1988): A novel twosite immunoradiometric assay for beta-endorphin using nitrocellulose as solid phase. Neurosci Biobehav Rev 12:199-204.

Yarbrough GG (1983): Thyrotropin releasing hormone and CNS cholinergic neurons. Life Sci 33:111-118.

Zaloga GP, Chemow B, Zajtchuk R, et al (1984): Diagnostic dosages of protirelin (TRH) elevate BP by noncatecholamine mechanisms. Arch Intern Med 144:1149-1152. 